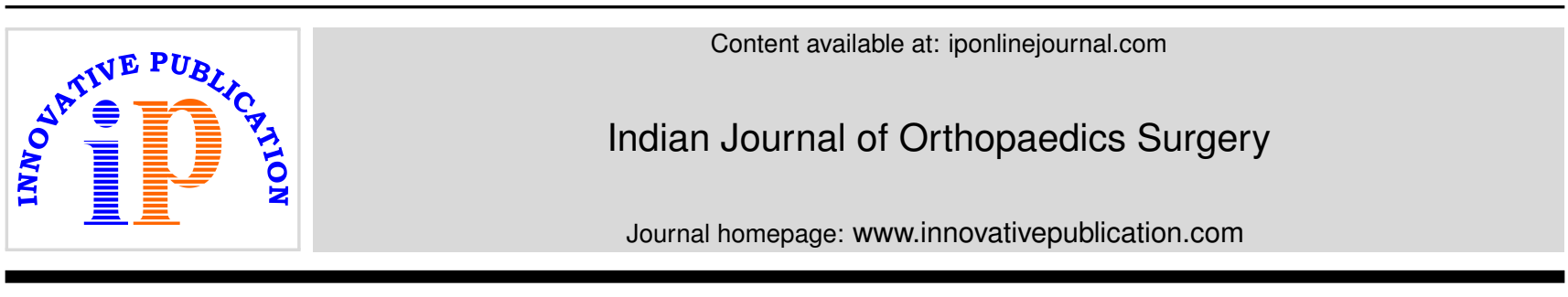

Original Research Article

\title{
A comparative study between laminectomy and laminotomy in patient of lumbar disc prolapse
}

\author{
Pinakin I Vora ${ }^{1} *$, Sanjay Kamol ${ }^{1}$ \\ ${ }^{1}$ Dept. of Orthopedics, Sir Takhtasinhji General Hospital, Bhavnagar, Gujarat, India
}

\section{A R T I C L E I N F O}

\section{Article history:}

Received 21-11-2019

Accepted 05-02-2020

Available online 21-04-2020

\section{Keywords:}

Disc Prolapse

Laminectomy

Laminotomy

\begin{abstract}
A B S T R A C T
Introduction and Objective: The study aims to compare the effectiveness of laminectomy and laminotomy for treating lumbar disc prolapse.

Materials and Methods: A prospective study of comparative study between laminectomy and laminotomy. In patient of lumbar disc bulge will be conducted in the department of Orhtopaedics, Sir Takhtsinhji Hospital, Bhavnagar, after getting permission from Institutional Review Board, Government Medical College, Bhavnagar. The Study will compose of 30 patients of lumbar disc bulge admitted in the Department of Orhtopaedics, Sir Takhtsinhji General Hospital, Bhavnagar. Patients will be included after approval of Institutional Review Board, Government Medical College, Bhavnagar. Detailed history regarding personal date, history of mechanism, pre- injury ambulatory status, preexisting local and systemic condition, menopausal status that may affect recovery. Full clinical examination will be done to assess the general condition of the patient, range of movement and any associated complains. MRI whole spine screening will be taken.

After deciding the appropriate plan, patient will be prepared for surgery. Every patient will be operated upon as early as possible or within two days of getting fitness for anesthesia. All patients will be assessed with regard to operative time day of getting fitness for anesthesia. All patients will be assessed with regard to operative time, blood loose, hospital stay and post operative complications. Dressing will be checked on the $2^{\text {nd }}, 4^{\text {th }}, 6^{\text {th }}$ post - operative day. Patients will be discharged and then after will be followed on $2^{\text {nd }} \mathrm{wk}$, $6^{\text {th }} \mathrm{wk}, 12^{\text {th }} \mathrm{wk}$, and $6^{\text {th }}$ month. On follow up visits patients' will be evaluated with odoms criteria, general and systemic examination.

Results: Laminotomy has definitive advantages over leminectomy in terms of SHORT hospital stay an average of 5 days, less blood loss, Less postoperative pain and Epidural hematomas and Fibrosis, It has the advantage that it's shorter length of hospitalization leads to early return to work thus improving the quality of life earlier.

Conclusion: The low complication rate makes laminotomy a choice of surgery in lumbar disc bulge.
\end{abstract}

(C) 2020 Published by Innovative Publication. This is an open access article under the CC BY-NC-ND license (https://creativecommons.org/licenses/by/4.0/)

\section{Introduction}

Schitic pain and back pain are the results human beings pay from Qudripedal to bipedal stance, prolonged sitting, repeated bending forward, mechanical stresses, increased lumbar lordosis, sedentary lifestyle leading to obesity, psychological stress, poor abdominal tone and poor spinal geometry. Low back pain is second after respiratory

\footnotetext{
* Corresponding author.

E-mail address: drpinakinivora@yahoo.in (P. I. Vora).
}

infections in terms of hours lost from work, as reported by Rowe's 10-year study. ${ }^{1}$

As estimation by Nachemson $80 \%$ people having back pain experiencing in their whole life. Among them $40 \%$ people show hearniated disc on MRI by 40 years of age. After episode of back pain $70 \%$ people resolve by three weeks and $90 \%$ people resolve by 1 month. Approximately $1 \%$ people continues to have symptoms even after one year.

Before invention of $\mathrm{x}$-ray and MRI, surgery were performed based on clinical findings only. William Conrad 
Roentgen invented X-rays and the evolution of spinal disorders entered a new path. In 1891, Heinrich Quincke do the groundwork for myelography and he had introduced the technique of lumbar puncture. The myelography was invented when the ventricular system of the brain was accidentally visualized on a post-traumatic skull $\mathrm{x}$-ray performed by Luckett in 1913. By 1922, Jean Sicard and Jacques Forestier had shown results of positive contrast myelography. However when effects of the herniated nucleus pulposus finally recognized, there was need for contrast medium.Ans then there was development of Pantopaque ethyl iodo-phenylundecylate) by Theodore Steinhausen and his colleagues at the University of Rochester during World War II. The new era came with the advent of the computerized tomography and magnetic resonance imaging. MRI introduced in the early 1970's and still today excellent guide in the evaluation of a patient with discogenic pain.

Lumbar disc herniations cases can be divided into nonoperative and operative treatment. Nonoperative treatment consists of bed rest; analgesia, specific physiotherapy, braces and injection therapy. Intrathecal steroids have also been used in some cases. Surgical treatment initially started with decompression through laminectomy. Though laminectomies were done for low back pain, radicular pain, difficulty in routine activity. Identification of intervertebral disc herniation causig radicular pain goes to Mixter and Barr's classical article in 1934, and they performed the laminectomy with discectomy to relieve Radicular pain. ${ }^{2}$ Since then there has been a lot of improvement and changes in, instrumentation, optics and surgical techniques. Depending on indications the herniated lumbar disc can be removed after doing laminectomy or through interlaminar approach with the help of special retractors using optical microscope or with the use of endoscope and by minimal radical surgry laminotomy. Our study aims to compare and check effectiveness and functional outcome of this laminectomy and laminotomy.

\section{Materials and Methods}

This prospective study group included 20 patients in each category of surgery, i.e, laminectomy and Laminotomy. All patients presenting to Sir T. civil Hospital, Bhavnagar with low backache and sciatica satisfying the inclusion criteria as mentioned below are included in this study. The study was conducted between 2018 to 2019.

\subsection{The inclusion criteria are}

1. All patients with low back pain, radicular pain and claudicatin diagnosed having lumbar disc prolapse and are candidates for surgical management.

2. Impaired motor skills
3. Difficulty in everyday activities, especially during bending/ lifting / standing

4. Difficulty in controlling bladder and bowel movement.

\subsection{Exclusion criteria}

1. Post traumatic sciatica equina syndrome.

2. Recurrent lumbar disc prolapse.

3. Those with involvement of cervical or thoracic disc along with lumbar discs.

4. Multiple disc prolapsed.

5. Cauda euqina syndrome.

All the patients included in this study underwent a thorough clinical and neurological examination as per the performa attached. They also underwent plain X- ray of the lumbo sacral spine AP, lateral and MRI of the lumbo sacral spine. $\$^{3}$ Laminectomy and discectomy were done to those patients with single or multiple level disc involvement associated with lumbar canal stenosis. Single level paracentral lumbar disc herniations were operated into laminotomy

\section{Surgical Procedure}

\subsection{Step 1: Patient preparation}

Lie on your back on the operative table and anesthesia will be given. The incision area is cleansed and prepared.

\subsection{Step 2: Incision}

A skin incision is made in the middle of the back over the appropriate vertebrae. The length of the incision depends on how many laminectomies are to be performed. The strong back muscles are split down the middle and moved to either side exposing the lamina of each vertebra.

\subsection{Step 3: Laminectomy or laminotomy}

Once the bone is exposed, an X-ray is taken to verify the correct vertebra. Laminectomy: The surgeon removes the bony spinous process. Next, the bony lamina is removed with a drill or bone-biting tools. The thickened ligamentum flavum that connects the laminae of the vertebra below with the vertebra above is removed. This is repeated for each affected vertebrae.

\subsection{Step 4: Decompression of the spinal cord}

Once the lamina and ligamentum flavum are removed the protective covering of the spinal cord (dura mater) is visible. Then one can retract protective sac of the spinal cord and nerve root to remove bone spurs and thickened ligament. 


\subsection{Step 5: Decompression of the spinal nerve}

The facet joints, which are directly over the nerve roots, may be trimmed to give the nerve roots more space. Foraminotomy can be performed, this maneuver enlarges the neural foramen (where the spinal nerves exit the spinal canal). If a herniated disc is there causing compression the surgeon cn do a discectomy.

\subsection{Step 6: Fusion}

If there is spinal instability and laminectomies to multiple vertebrae, a fusion can be performed. Fusion is the joining of two vertebrae with a bone graft fused together with implants such as plates, rods, hooks, pedicle screws, or cages. The goal of the bone graft is to join the vertebrae above and below to form one solid single piece of bone.

The most common type of fusion is the posterolateral fusion. The topmost layer of bone on the transverse processes is removed with a drill to create a bed for the bone graft to grow. Bone graft, taken from the top of hip, is placed along the posterolateral bed. The surgeon can do the fusion with metal rods and screws inserted into the vertebrae. The back muscles are laid over the bone graft to hold it in place.

\subsection{Step 7: Closure}

The muscle, fascia, and skin is sutured layerwise.

All the patients were sent to the postop ward. For laminectomy discectomy IV analgesia given for three days then shifted to analgesic oral tablets. The requirement of analgesia was noted as nil when the patient did not require any analgesia for 24 hours. All the patients in the study were operated under general anesthesia. ${ }^{4}$

The follow up was carried out in the $1^{\text {st }}, 6^{\text {th }}, 12^{\text {th }}$ week and $6^{\text {th }}$ month post op based on Odom's criteria, which is as under:-

Grade I (Poor) No improvement, increased deficit.

Grade II (Fair) Mild improvement, mild residual deficit.

Grade III (Good) Moderate improvement, mild residual deficit.

Grade IV (Excellent) Marked improvement, no deficit.

\subsection{Statistics}

Data was processed using Excel software programme. To compare the mean of the two groups, analysis of variants (Anova) and ' $f$ ' statistic was used with appropriate degree of freedom and level of significance. Observations are represented as pie charts and bar diagrams. Inter group comparison was carried out wherein two groups were compared for the difference in the mean value using student ' $\mathrm{T}$ ' test.
Table 1:

\begin{tabular}{lcc}
\hline $\begin{array}{l}\text { Age Group In } \\
\text { Year }\end{array}$ & $\begin{array}{c}\text { Number of } \\
\text { Cases }\end{array}$ & Percentage \% \\
$0-10$ & 0 & 00 \\
$11-20$ & 0 & 00 \\
$21-30$ & 01 & 3.33 \\
$31-40$ & 08 & 26.66 \\
$41-50$ & 06 & 20 \\
$51-60$ & 11 & 36.66 \\
$61-70$ & 04 & 13.33 \\
\hline
\end{tabular}

Table 2:

\begin{tabular}{lcc}
\hline Sex & Number of Cases & Percentage \\
Male & 16 & 53.33 \\
Female & 14 & 46.66 \\
\hline
\end{tabular}

Table 3:

\begin{tabular}{lcc}
\hline Type of Disc bulge & Number of Cases & Percentage \% \\
Rt Paraentral & 11 & 36.66 \\
Lt Paraentral & 06 & 20 \\
Central & 13 & 43.33 \\
\hline
\end{tabular}

\section{Discussion}

In this study group, the peak incidence was seen in the $5^{\text {th }}$ decade (mean age $48 \mathrm{yrs}$ ), as against the $3^{\text {rd }}$ to the $5^{\text {th }}$ decade seen in clinical practice, this is due to the fact that this study group involves LABOURER practising rigorous physical activity during their routine daily duties. Herniated disc is commonly seen among men (60\%), our study showed a much higher incidence in males ${ }^{5}$ because heavy physical activity seen in males because of their occupation. Central disc herniation was the most common herniation in this study. ${ }^{5}$ As per available literature commonest level involved is the L5 S1 disc followed by L4-5, L3-4 and L2-3 discs. The findings in our study were L4L5 disc involvement was seen in 13 patients (43\%) followed by L3 L4 disc, 05 patients (17\%), L5 S1, 05 patients (17\%), L2-3, 02 patient (7\%) and The rest were accounted by combined L2-3, L3 L4 04 patients (13\%), L3 L4,L4 L5 was seen in 01 patient (3\%). ${ }^{6-8}$

The entire study group underwent plain X-ray of the lumbar spine followed by MRI of the lumbar spine. In our study MRI of the lumbar spine gave an accurate details of the anatomy of the spine and the pathology involved and was performed in all the cases. ${ }^{3}$ Even in the literature MRI is said to be the most practical imaging study for evaluation of patients with lumbar radicular symptoms.

In all patients of our study, the indications for surgery were absolute. Dural tear was encountered in one case in the Laminotomy group which required converted to open procedure after the initial Laminotomy to repair the tear. Dural tear is seen in $4 \%$ of cases of Laminotomy and in this study it was 3\% (01 patient). Case no 7 in the laminectomy discectomy group, had increased neurological deficit in the 
Table 4:

\begin{tabular}{lccccccccccc}
\hline $\begin{array}{l}\text { Stay In } \\
\text { Hospital }\end{array}$ & 01 & 02 & 03 & 04 & 05 & 06 & 07 & 08 & 09 & 10 & Mean \\
$\begin{array}{l}\text { LAM } \\
\text { Number of }\end{array}$ & 00 & 00 & 00 & 00 & 00 & 00 & 00 & 05 & 06 & 04 & $134 / 15$ \\
$\begin{array}{l}\text { Cases } \\
\text { LMO }\end{array}$ & 00 & 00 & 03 & 07 & 05 & 00 & 00 & 00 & 00 & 00 & $67 / 15=4.46$ \\
$\begin{array}{l}\text { Number of } \\
\text { Cases }\end{array}$ & & & & & & & & & & &
\end{tabular}

early follow up, however there was complete recovery by 6 months. There were no other complications encountered.

Table 5:

\begin{tabular}{lcc}
\hline $\begin{array}{l}\text { Grading (odoms } \\
\text { crieteria) }\end{array}$ & \multicolumn{2}{c}{ Number of Cases } \\
Excellent & LAM & LMO \\
Good & 03 & 05 \\
Fair & 06 & 06 \\
Poor & 06 & 04 \\
\hline
\end{tabular}

It has been found in this study that the least hospitalization was seen in Laminotomy (4 days), followed by laminectomy discectomy ( 8.9 days). Whereas the average duration of hospitalization mentioned in the literature for Laminotomy is 2.76 days and 7.14 days for laminectomy discectomy. Since our hospital being a service hospital serving to personnel of the all heavy worker and labourer hence the patients were kept in the hospital for a longer time.

Also the requirement of post op analgesia was least in Laminotomy, followed by laminectomy discectomy group.

When the mean duration of stay and the requirement of post op analgesia across the groups was compared, it was found that the difference in the mean duration of stay and post op analgesia was statistically significant $(\mathrm{p}<0.001)$. In our study it is sound that LAMINOTOMY patients had an earlier postoperative ambulation, reduced intraoperative blood loss and decreased postoperative consumption of analgesic medications.

Table 6: Comparision of post op analgesia between the 2 groups

\begin{tabular}{lcc}
\hline & Lam & Leminotomy \\
Mean & 4.46 & 2.4 \\
SD & 0.51 & 0.50 \\
\hline
\end{tabular}

Inter group comparison was carried out wherein every two groups were compared for the difference in the mean values using a students ' $t$ ' test. This inter group comparison indicated that the difference in the mean duration of stay and post op analgesia was statistically significant among the groups $(\mathrm{p}<0.001)$. The requirement of post op analgesia was least with laminotomy followed by laminectomy. This significance is because of the type of surgery performed in the two groups ranging from open surgery to less invasive surgery to minimally invasive surgery. The only limiting factor is the high cost of the endoscope and the learning curve as the surgeon has to operate in a tunnel with an endoscope, which, unlike an operating microscope provides only a 2D image.

When the post up status, as assessed by Odom's criteria at $1^{s t}, 6^{t h}$, and $12^{\text {th }}$ week and $6^{\text {th }}$ month were plotted against the number of patients for the laminectomy discectomy group, as shown in Figure, it can be seen that the majority of the patients were in the Grade III (12 patients), followed by Grade II (10 patients), Grade IV (03 patients), and Grade I (01 patient), during the entire duration of follow up extending for 6 months.

\section{Conclusion}

Recent days a lot of improvements in the surgical management of lumbar disc prolapse cases due to improvement in instrumentation, implants, optics and techniques. This led to the transition from old technique (larger incision, wide exposure for laminectomy and discectomy) to the less invasive laminotomy. Lumbar laminectomy and discectomy still can be performed for cases of lumbar disc prolapse with primary bony lumbar canal stenosis or secondary lumbar canal stenosis due to thickened ligamentum flavum hypertrophy. Patient presenting with cauda equina syndrome due to lumbar disc herniation needs decompression laminectomy and discectomy for early and complete neurological recovery. However in the present scenario laminectomy discectomy is not indicated for single disc, single level disc herniation. For single level paracentral disc herniation, the new technique microendoscopic discectomy is preferred being a minimally invasive technique with quick postoperative recovery and less hospitalization period. The only limiting factor is the high cost of the endoscope and the learning curve of the surgeon to perfect the skills of this technique. Laminotomy has become gold standard in the surgical management of lumbar disc herniation due to its excellent postoperative results. In laminotomy procedure it does not damage the spinous process and critical ligaments so there is not as much muscle weakness, pain and lumbar Instability. As compare to laminectomy less post-operative complications and early mobilisation (ambulation) makes the laminotomy 
better choice in case of lumbar disc prolapse. ${ }^{9,10}$

\section{Summary}

1. The study included a total of 30 patients, fifteen in each group, i.e, laminectomy discectomy, laminotomy. 16 males and 14 females

2. The mean age is $50 \mathrm{yrs}$ (range $21-75 \mathrm{yrs}$ ). The peak incidence was in the 5 th decade $(36.66 \%)$.

3. Central disc herniation was the commonest accounting to $86.66 \%$ (26) of cases.

4. MRI of the lumbar spine gave an accurate depiction of the anatomy of the spine and the pathology involved and was performed in all the cases.

5. There was only one complication in the Laminotomy group in the form of dural tear which was successfully managed by conversion to open procedure.

6 . There was 1 post op infection, postoperative complications encountered, which was recovered later on.

7. Of the 15 operated cases in the laminectomy discectomy group, one patient had increased neurological deficits post surgery which resolved completely at 6 month follow up.

8. The patients of the laminotomy group had a better post operative status, as per Odom's criteria and the requirement of post op analgesia and duration of hospitalisation was significantly less as compared to the patients of laminectomy discectomy group.

\section{Source of Funding}

None.

\section{Conflict of Interest}

None.

\section{References}

1. Rowe ML. Low Back Pain in Industry. J Occup Environ Med. 1969;11(4):161-9.

2. Deyo RA. Early diagnostic evaluation of low back pain. J Gen Intern Med. 1986;1(5):328-38.

3. Borenstein DG, O'Mara JW, Boden SD, Lauerman WC, Jacobson A, Platenberg $\mathrm{C}$. The value of magnetic resonance imaging of the lumbar spine to predict low-back pain in asymptomatic subjects. J Bone Joint Surg Am. 2001;83(9):1306-11.

4. Truumees E. A History of Lumbar Disc Herniation From Hippocrates to the 1990s. Clin Orthop Relat Res. 2014;473(6):1885-95.

5. Heliovaara M. Epidemiology of sciatica and herniated lumbar intervertebral disc. Helsinki, Finland: The Social Insurance Institution; 1988.

6. Postacchini F, Cinotti G. Etiopathogenesis. In: F P, editor. Lumbar disc herniation. New York: Spring-Verlag; 1999. p. 151-64.

7. Friberg S, Hirsch C. Anatomical and Clinical Studies on Lumbar Disc Degeneration. Acta Orthop Scand. 1949;19(2):222-42.

8. Schultz A, Andersson G, Ortengren R, Haderspeck K, Nachemson A. Loads on the lumbar spine. Validation of a biomechanical analysis by measurements of intradiscal pressures and myoelectric signals. J Bone Jt Surg. 1982;64(5):713-20.

9. Shetty AP, Kanna RM, Avadhani A, Rajasekaran S. Lumbar spinous process split decompression. Eur Spine J. 2010;19(2):357-8.

10. Munting E, Röder C, Sobottke R, Dietrich D, Aghayev E. Patient outcomes after laminotomy, hemilaminectomy, laminectomy and laminectomy with instrumented fusion for spinal canal stenosis: a propensity score-based study from the Spine Tango registry. Eur Spine J. 2015;24(2):358-68.

\section{Author biography}

Pinakin I Vora Associate Professor

Sanjay Kamol 3rd Year Resident, Principal Investigator

Cite this article: Vora PI, Kamol S. A comparative study between

laminectomy and laminotomy in patient of lumbar disc prolapse. Indian J Orthop Surg 2020;6(1):25-29. 